11-20-1981

\title{
Mid-level intrusions at the continental shelf edge
}

Christopher S. Welch

Virginia Institute of Marine Science

Follow this and additional works at: https://scholarworks.wm.edu/vimsarticles

Part of the Marine Biology Commons, and the Oceanography Commons

\section{Recommended Citation}

Welch, Christopher S., "Mid-level intrusions at the continental shelf edge" (1981). VIMS Articles. 296.

https://scholarworks.wm.edu/vimsarticles/296 


\title{
Mid-Level Intrusions at the Continental Shelf Edge
}

\author{
CHRISTOPHER S. WelCH \\ Virginia Institute of Marine Science and School of Marine Science, The College of William and Mary
} Gloucester Point, Virginia 23062

\begin{abstract}
Observations across the continental shelf offshore from New Jersey in late summer 1976 show an intrusion of saline water at the mid level of the water column across the shelf edge front, which appears in density only as an offshore thickening of the pycnocline. This internal density field produces horizontal pressure gradient forces within the pycnocline in the onshore direction. These forces, in the linearized equation of motion with a constant eddy viscosity, drive a circulation which resembles a double Ekman spiral for internal pressure vertical distributions which are thin with respect to the Ekman depth. For thick pressure distributions, the circulation is geostrophic. The resulting flow pattern has no net crossshelf transport. For the continental shelf edge in the example, a northward geostrophic mid-level jet is predicted by the theory. Ekman depth, and thus the vertical coefficient of eddy viscosity, can be determined from hydrographic data describing an intrusion.
\end{abstract}

\section{INTRODUCTION}

The east coast of the United States north of Cape Hatteras is characterized by a broad, shallow continental shelf, over which an identifiable water mass called shelf water forms [Bigelow, 1933]. At the seaward edge of the shelf, the ocean depth increases abruptly by a factor of 10 . Nearly coincident with this depth increase, a water mass boundary is observed between the shelf water, freshened by runoff, and the saltier slope water. Often this boundary, the shelf edge front, is density compensating, the horizontal temperature and salinity gradients having compensating effects on density so that isopycnals through the front are relatively level. During the warm season of the year, this density compensating condition is often met even though a substantial summer thermocline forms on both sides of the front. On occasion, fresh water from the shelf is found in mid-level lenses on the seaward side, and slope water is found on the landward side of the front. The purpose of this paper is to report observations of this cross-frontal exchange in the Middle Atlantic Bight, to present a hypothesis concerning one cause of the exchange, and to examine some consequences of the hypothesis.

\section{Previous Work}

The phenomenon of shelf water in isolated patches offshore and oceanic water over the continental shelf, named 'calving' by Cresswell [1967], has received attention for several reasons. The resulting layers always produce regions in which salt finger instabilities can occur [Turner, 1967; Posmentier and Houghton, 1978]. In addition, the structure has been used to examine oceanic mixing rates and shelf-ocean exchanges [Joyce, 1977; Voorhis et al., 1976; Horne, 1978]. Various investigators have called similar features 'lenses,' 'laminae' [Stommel and Federov, 1967], 'intrusions' [Bigelow and Sears, 1935], and 'interleaving' [Horne, 1978]. These descriptive terms indicate that the anomalous water parcels can appear to be continuous with their sources or detached, as observed in a hydrographic section. In all instances, the presence of these parcels is indicated by a specific pattern of temperature-salinity correlation at a vertical station. The pattern consists of a sequence of zigzag lines which traverse relatively large dis-

Copyright (C) 1981 by the American Geophysical Union. tances in temperature-salinity space while maintaining a monotonic increase in density. These patterns, usually associated with the shelf edge front, have been reported along the North American east coast off the Scotian Shelf [Horne, 1978], in the vicinity of Georges Bank [EG\&G, 1978], offshore from New York [Posmentier and Houghton, 1978], New Jersey [Ruzecki et al., 1977], and Maryland [Boicourt and Hacker, 1976], to the North Carolina shelf edge just north of Cape Hatteras [Curtin, 1979]. The mid-level intrusions thus appear to occur at times along the entire shelf edge front during the stratified season.

In the northern part of the Middle Atlantic Bight, particularly in the spring, the shelf edge front is evident in density cross sections as well as temperature and salinity patterns. Examples are shown in the works by Cresswell [1967], Beardsley and Flagg [1976], and Voorhis et al. [1976]. Frontal structure in such cases is consistent with a horizontal shear in the geostrophic current [Voorhis et al., 1976], and current measurements have indicated shear in the right sense, although with diminished magnitude, when compared with the geostrophic calculations [Beardsley and Flagg, 1976]. Further to the south, offshore from New York, Gordon and Aikman [1981] have noted a persistent salinity maximum during summer and late autumn at mid depth associated with the shelf edge front when a range of isopycnals crossing from slope water into shelf water is present. Posmentier and Houghton [1981] show that the cross-shelf shape of the front is consistent with Margules' relation for geostrophic frontal slopes on the assumption of a $5-\mathrm{cm} / \mathrm{s}$ horizontal difference in front-parallel currents across the front, an assumption consistent with conclusions of Beardsley and Flagg [1976]. The Posmentier and Houghton [1981] August 1979 section shows not only isopycnals continuous across the front, but a range of depths for which isopycnal surfaces crossing the front are nearly level, a density balanced condition. Further to the south, off the coast of Maryland, Boicourt and Hacker [1976] have shown an extensive density balanced salinity intrusion crossing much of the shelf. They interpret the intrusion as a compensatory flow in response to offshore Ekman transport caused by strong southerly winds. In summary, cross-frontal intrusions are associated with a variety of density structures from steeply sloping density fronts with few isopycnals crossing the front toward the north and in the spring to density balanced fronts toward the south and later in the summer. 


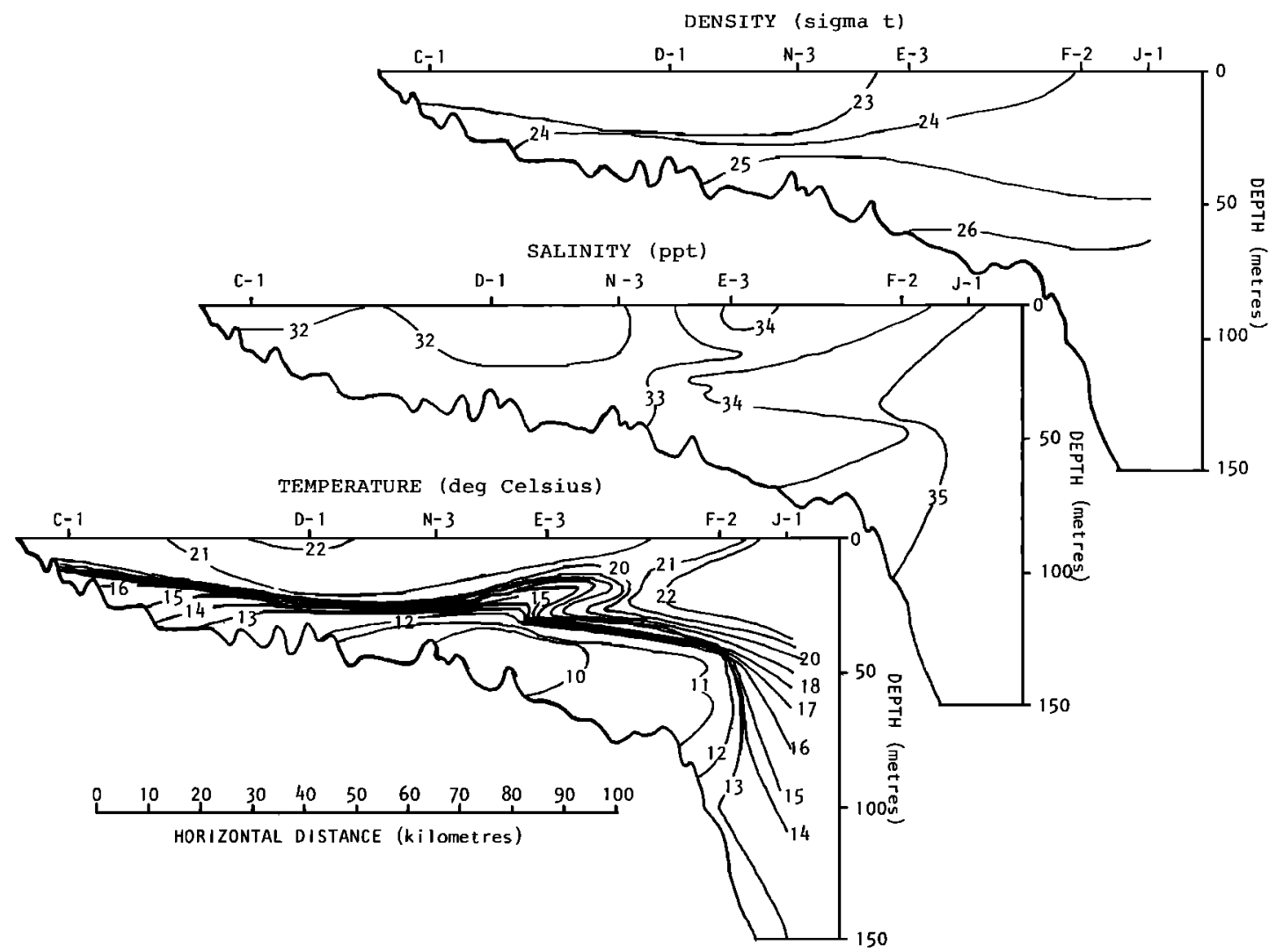

Fig. 1. Temperature (in degrees Celsius) salinity (in parts per thousand), and density (in $\sigma_{1}$ units) in a cross-shelf section offshore from Atlantic City, New Jersey, September 1976. Data are from Ruzecki et al. [1977].

\section{A Density Balanced Example}

The following example [Ruzecki et al., 1977] indicates a mid-level intrusion and the surrounding cross-shelf hydrography. Figure 1 shows a composite cross section of temperature, salinity, and density along a transect offshore from New Jersey during late summer (September 1976). The intrusion is evident in the sections of temperature and salinity between station E-3 and the shelf edge. The isopycnals associated with the intrusion are smooth, the principal feature being that the pycnocline shoreward of that point is much thinner than that further offshore. The temperature-salinity correlation at station E-3 with points plotted at $\frac{1}{2}-\mathrm{m}$ intervals exhibits the zigzag character associated with similar intrusions (Figure 2). The thickness of the intrusion is $13 \mathrm{~m}$. The intrusion is also evident in the station soundings for temperature and salinity at station E-3 (Figure 3). A feature of interest in this example is the coincidence of the intrusion with the region in which the vertical density gradient varies horizontally, changing from large values in the shelf summer pycnocline to smaller values in the deep water offshore. In what follows, the horizontal change of vertical density gradient is considered to be an essential condition for the occurrence of mid-level intrusions through density balanced fronts.

\section{HYPOTHESIS}

Shelf mixing processes produce a density field which in turn produces a mid-level onshore-directed relative pressure gradient force. This force drives a relative motion governed by friction and Coriolis acceleration. The shelf mixing processes pro- duce a nearly two-layer density structure over the shelf. At the Middle Atlantic Bight shelf edge, the layers are the surface mixed layer and the cold pool. The region between these layers is quite thin. Observed pycnoclines less than $10 \mathrm{~m}$ thick are common in the mid-shelf region during the summer. The hypothesized shelf mixing processes are absent or less effective in the vertically less confined deep water offshore from the shelf edge. Hence the pycnocline is thicker offshore. Offshore thickening of the summer pycnocline is also frequently observed. Under hydrostatic conditions, this density structure implies a relative horizontal onshore-directed force at the mid level in the region of transition between the two pycnocline

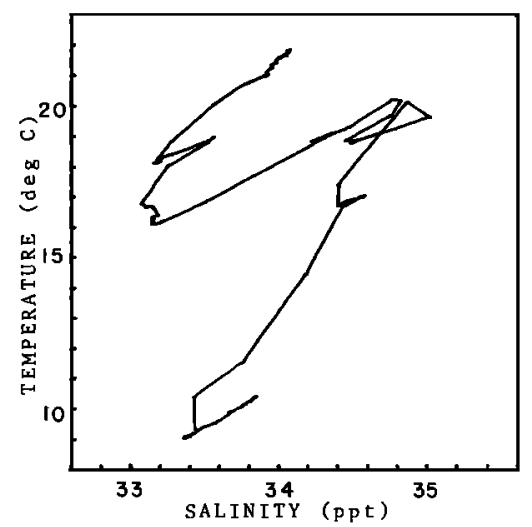

Fig. 2. Temperature-salinity correlation at station E-3. Station location is shown in Figure 1. 


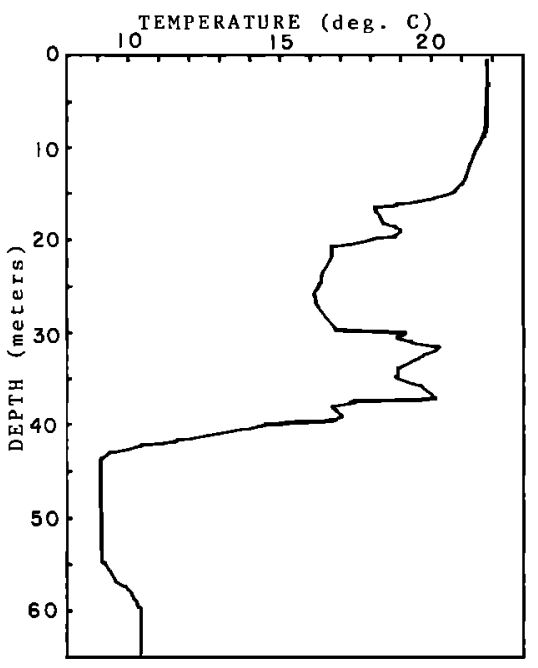

Fig. $3 a$.

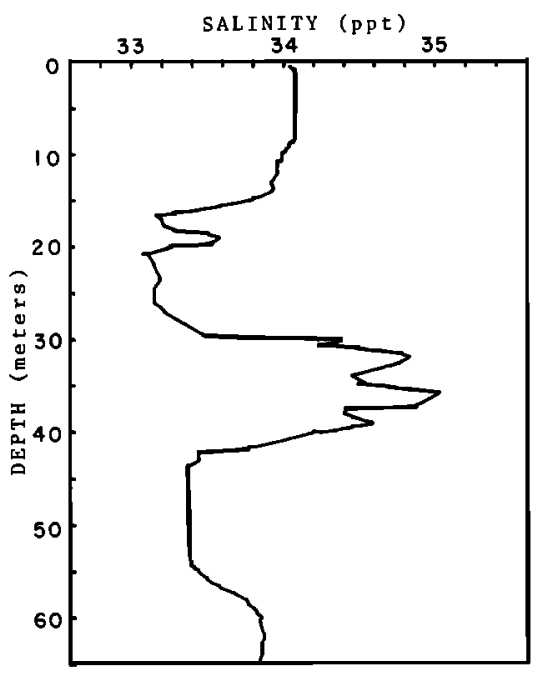

Fig. $3 b$.

Fig. 3. (a) Temperature and (b) salinity versus depth at station E-3. Station location is shown in Figure 1.

thicknesses, shown schematically in Figure 4. In Figure 4a, the hypothesized isopycnals are illustrated in a section crossing the shelf edge. Two vertical lines, $A$ and $B$, are chosen for calculation of relative hydrostatic pressure, the pressure which results from the assumption of a level sea surface. An additional pressure field, having a constant horizontal gradient with depth, is associated with a surface slope. Figure $4 b$ shows density as a function of depth at the two analysis stations, with Figure $4 c$ showing the corresponding hydrostatic pressure difference. The pressure difference, divided by the distance between the stations, gives the average horizontal pressure gradient between the analysis stations, and the resulting force (Figure $4 d$ ) is directed onshore at only the mid levels of the water column. In the next section, the motion driven by this pressure gradient force is assumed to be governed, to a first approximation, by steady rotational horizontal flow with vertical frictional shear stresses, i.e., Ekman dynamics.

\section{Mathematical Formulation}

The assumption is made that the adjustment time of the flow to the pressure field is much shorter than the time re- quired to change the pressure field due to the rearrangement of mass as a consequence of the flow. Under these conditions, the flow field is nearly described as a steady state balance with an unchanging density field, and so the pressure field associated with the density field can be considered as an external force. Following Hidaka [1955], the horizontal momentum equations are written as

$$
\begin{gathered}
-f v-\nu \frac{\partial^{2} u}{\partial z^{2}}=-\frac{1}{\rho} \frac{\partial p}{\partial x} \\
f u-\nu \frac{\partial^{2} v}{\partial z^{2}}=0
\end{gathered}
$$

Here, $u$ and $v$ are the velocity components in the $x$ and $y$ (offshore and alongshore, e.g., east and north) directions, respectively; $z$ is positive upward measured from the maximum of the pressure force; $\rho$ is the water density; $f$ is the Coriolis parameter $f=2 \Omega \sin \phi$ where $\Omega$ is the magnitude of the angular velocity of the earth and $\phi$ is the latitude); and $\nu$ is the dynamic eddy viscosity of the water, assumed constant here. As the pressure gradient force is assumed to act only in the $x$ direction (normal to the coast) and is constant in time, let it be replaced by an arbitrary function.

$$
-\frac{1}{\rho} \frac{\partial p}{\partial x} \equiv h(x, z) \quad h \rightarrow 0 \quad \text { as } \quad x, z \rightarrow \pm \infty
$$
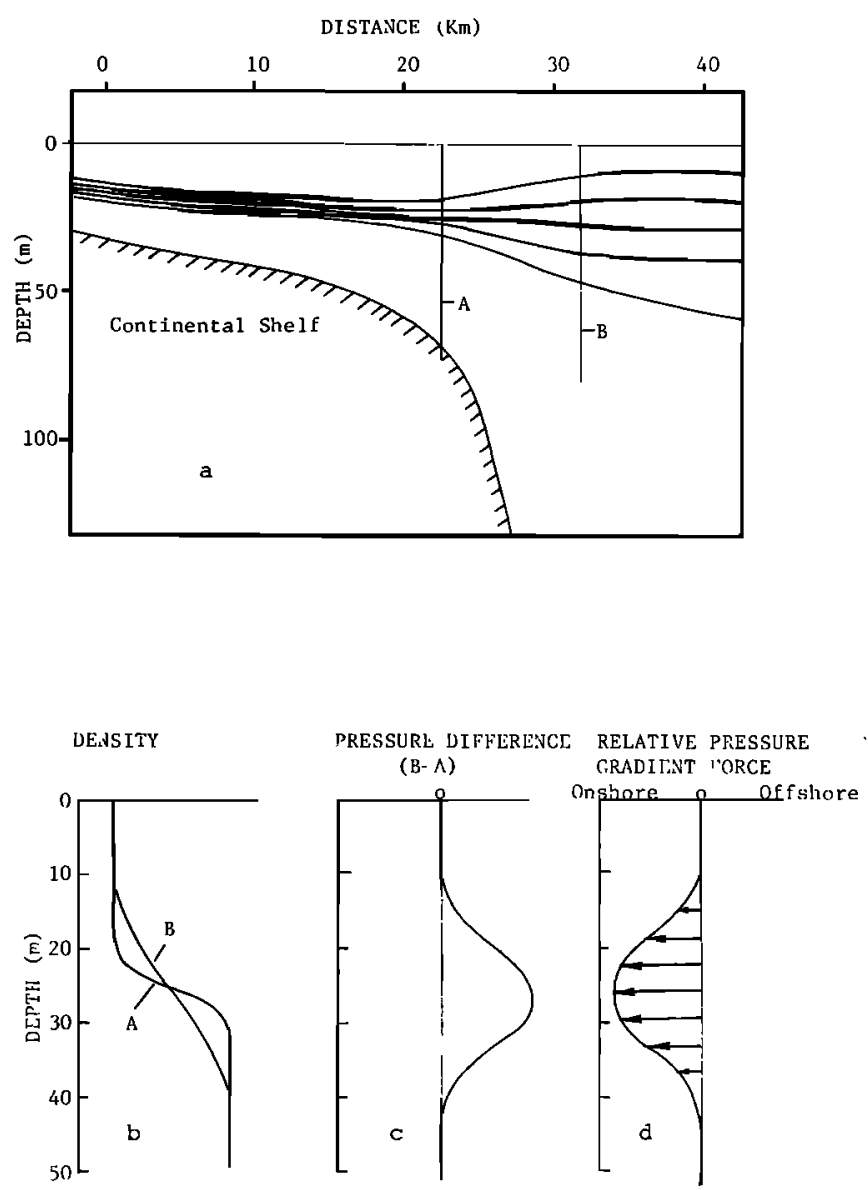

Fig. 4. (a) Schematic density structure in a cross-shelf section at the continental shelf edge. Vertical profiles $A$ and $B$ are selected to illustrate horizontal differences in $(b)$ density and $(c)$ pressure resulting in $(d)$ an onshore pressure gradient force. 
Following Hidaka [1955], (1) reduces to a single second-order complex equation with the introduction of a complex velocity variable

$$
w=u+i v
$$

resulting in

$$
\frac{\partial^{2} w}{\partial z^{2}}-i \frac{f}{\nu} w=-\frac{h}{\nu}
$$

Defining an inverse length scale, the Ekman scale,

$$
\alpha=\mid\left(\left.\frac{f}{2 \nu}\right|^{1 / 2} \mid\right.
$$

the solution to the homogeneous part of the equation is

$$
w_{h}=C_{1} e^{(1+i) \alpha z}+C_{2} e^{-(1+i) \alpha z}
$$

These are the two Ekman layer solutions. For the inhomogeneous case, the $C$ can be treated as functions of depth which yield, under the given assumptions,

$$
\begin{aligned}
& C_{1}=-\frac{1}{2(1+i) \alpha \nu} \int_{x}^{\infty} h(x, \xi) e^{-(1+i) \alpha \xi} d \xi \\
& C_{2}=-\frac{1}{2(1+i) \alpha \nu} \int_{-\infty}^{z} h(x, \xi) e^{+(1+i) \alpha \xi} d \xi
\end{aligned}
$$

In particular, a very thin pressure disturbance at a level of $z_{0}$ can be represented as

$$
h(x, z)=h_{0}(x) \delta\left(z-z_{0}\right)
$$

where $\delta\left(z-z_{0}\right)$ is the Dirac delta function and $h_{0}$ has units of $h \times$ length, or (velocity) ${ }^{2}$. The corresponding complex velocity function is the Green's function for the general solution, $G(z)$ [Hidaka, 1955]. The Green's function has the additional property that the solution of $w$ for an arbitrary $h$ can be expressed as

$$
w(z)=\frac{1}{h_{0}} \int_{-\infty}^{\infty} h(y) G(z-y) d y
$$

Evaluating the Green's function as the velocity field resulting from a very thin pressure perturbation at level $z_{0}$ gives

$$
\begin{array}{ll}
G(z)=-\frac{h_{0}}{2(1+i) \alpha \nu} \exp \left[(1+i) \alpha\left(z-z_{0}\right)\right] & z<z_{0} \\
G(z)=-\frac{h_{0}}{2(1+i) \alpha \nu} \exp \left[-(1+i) \alpha\left(z-z_{0}\right)\right] & z>z_{0}
\end{array}
$$

or

$$
G(z)=-\frac{(1-i) h_{0}}{4 \alpha \nu} \exp \left[-(1+i) \alpha\left|z-z_{0}\right|\right]
$$

The real (offshore) and imaginary (alongshore) parts of this solution describe Ekman spirals extending above and below the level of the pressure perturbation (Figure 5). Figure 6 illustrates the corresponding plan view of the resultant velocity as well as the net transport associated with this particular solution. The net transport is in the alongshore direction.

The net transport due to a general onshore pressure gradient force is also directed alongshore. This can be seen by integrating (7) vertically to calculate the transport. The result is

$$
T \equiv \int_{-\infty}^{\infty} w(z) d z=\frac{1}{h_{0}} \int_{-\infty}^{\infty} \int_{-\infty}^{\infty} h(y) G(z-y) d y d z
$$

Changing the order of integration gives

$$
T=\frac{1}{h_{0}} \int_{-\infty}^{\infty} h(y) \int_{-\infty}^{\infty} G(z-y) d z d y
$$

With a translation of variables, the inner integral becomes the transport for the Green's function velocity, which has zero real (onshore) part so the outer integral will also have zero net onshore transport. Thus, the flow for an arbitrary onshore pressure gradient limited to mid depth can cause cross-shelf exchange of water, but not net cross-shelf transport.

For a pressure gradient force remaining nearly constant over a depth range much larger than the Ekman depth, the governing equations (equations (1)) reduce to the geostrophic balance, as the $z$ derivative term becomes negligible. The solution of the equations also reduces to the geostrophic velocity in such a region, verified by integrating (7) with a vertically constant $h$ and substituting into the solution form. Thus, with a thick layer of driving force, an interior geostrophic region is produced with flow in the alongshore direction. For the east coast of the United States, this geostrophic, mid-level flow would be toward the north for an onshore pressure gradient force, corresponding to a pycnocline thickening offshore.

\section{A Conceptual Flow Model}

With the Green's function, the internal flow field associated with a given hydrographic section can be calculated except that the value for kinematic viscosity remains undetermined. A conceptual model for the relative flow field at the shelf edge can also be formulated given only that the perturbing pressure gradient occupies a vertical extent greater than the Ekman depth on its seaward side and less than the Ekman depth on its shelf side. This density field and the accompanying flow field are illustrated schematically in Figure 7. The flow field has a geostrophic core on the seaward side of the region of pycnocline thickening with an interleaving pattern on the landward side. The geostrophic core of current forms a continuous band along the entire length of the shelf edge over which the shelf mixing processes tend to sharpen the pycnocline. The interleaving flow tends to thicken the pycnocline on its shoreward side, thereby reducing the relative pressure gradient which drives the flow.

Because the flow is entirely a response to the internal pressure field, it is of interest to estimate the velocity in the geostrophic core, for it may be so small that the entire flow pattern is negligible. Considering summer conditions, the pycnocline in the Middle Atlantic Bight can have a density contrast of $4 \sigma_{t}$ units. Using a $4 \sigma_{t}$ pycnocline with a thickness of $10 \mathrm{~m}$ at the shelf edge increasing to $50 \mathrm{~m}$ on the ocean side over a width of $10 \mathrm{~km}$, an estimate of the maximum pressure gradient in the center of the pycnocline can be made. The estimate from the hydrostatic equation using, as an average, half the maximum density difference $(\Delta \rho)$ over half the difference of the offshore-onshore thermocline thickness $(T)$ is

$$
\left|\frac{1}{\rho} \frac{\partial p}{\partial x}\right|=\frac{1}{\rho} g\left|\int_{z_{0}}^{\text {Surface }} \frac{\partial \rho}{\partial x} d z\right| \simeq \frac{g}{\rho} \frac{\frac{1}{2}(\Delta \rho / 2)}{\Delta x} \frac{T}{2}
$$

or

$$
\left|\frac{1}{\rho} \frac{\partial p}{\partial x}\right| \simeq 2 \times 10^{-3} \frac{\mathrm{cm}}{\mathrm{s}^{2}}
$$



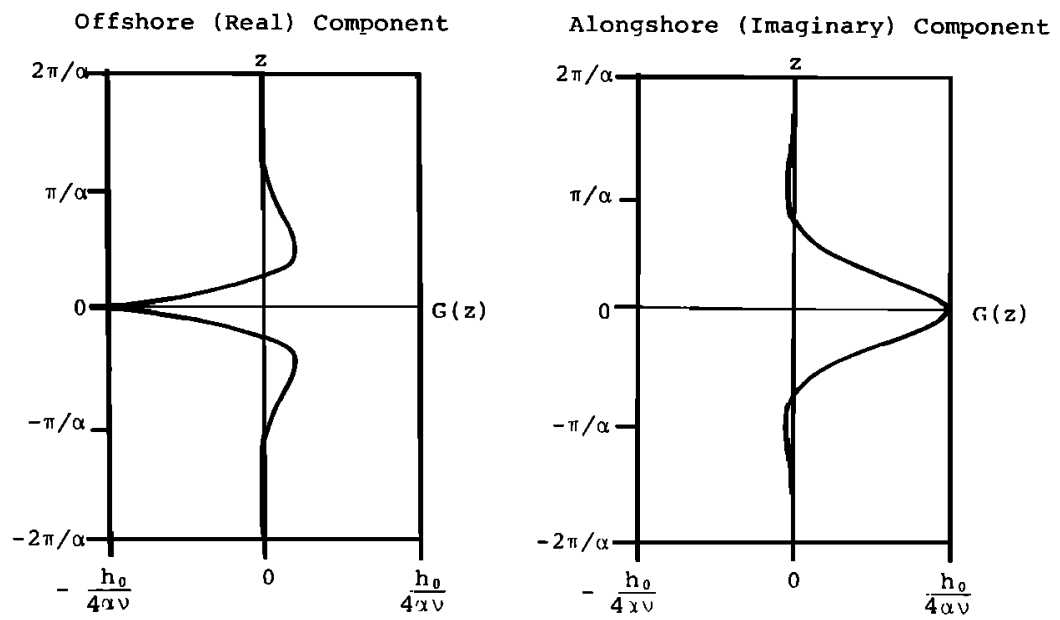

Fig. 5. Real (offshore) and imaginary (alongshore) components of the Green's function, $G(z)$. The Green's function can be interpreted as the velocity hodograph due to a very thin onshore pressure gradient force at $z=0$.

This estimate yields a geostrophic velocity of $20 \mathrm{~cm} / \mathrm{s}(\sim 20$ $\mathrm{km} /$ day), using $10^{-4} \mathrm{~s}^{-1}$ for the Coriolis parameter. Such a velocity would transport material from south of Cape Hatteras to the latitude of Chesapeake Bay in about 10 days.

In the left part of Figure 7, indicated as a thin layer, the solution approaches the Green's function. From (9), the maximum and scale value of the speed is

$$
\left|G\left(z_{0}\right)\right|=\frac{2^{1 / 2} h_{0}}{4 \alpha \nu}=\frac{2^{1 / 2} \int_{-\infty}^{\infty}(1 / p) \nabla_{H} p d z}{4(f \nu / 2)^{1 / 2}}
$$

Scaling the integral as the product of the maximum pressure gradient and the thickness $(D)$ of the layer, a modest overestimate, and denoting as $v_{g}$ the geostrophic velocity (1/ $\rho)\left(\nabla_{H} p / f\right)$ and as $L$ the Ekman scale depth $1 / \alpha$ or $(2 v / f)^{1 / 2}$, the result is

$$
\left|G\left(z_{0}\right)\right|=2^{-1 / 2} v_{g} D / L
$$

This indicates that the velocity in the thin part of the pattern has a maximum value of $v_{g}$ times the ratio of the layer thickness to the Ekman scale dèpth. This ratio is less than unity if the thin layer approximation is valid. Thus, the flow field can be visualized as geostrophic 'pipeline' extending slightly offshore from the shelf edge with an Ekman-like 'vane' with lower speeds extending onshore, developing an interleaving pattern as the pycnocline thickness becomes less than the Ekman depth (Figure 7).

\section{7. applications to Middle atlantic BIGHT DATA}

Several inferences can be based on the conceptual flow pattern. The first is an estimate of $\nu$, the vertical eddy viscosity at the continental shelf edge when intrusions are present. The most convincing reason for the absence of Ekman spirals in the surface and bottom boundary layer observations is that the vertical turbulent transfer of horizontal momentum is so complex and changes character over such a short length adjacent to the boundaries that relating it to mean shear with a coefficient of viscosity, let alone one of constant value, simply does not describe the momentum transfer well. In the interior of the fluid, a slowly varying viscosity coefficient is more plausible because transitions in the medium as abrupt as a free surface or bottom boundary are not present. Thus, spirals can be expected in the interior having a vertical scale which depends on the viscosity coefficient; hence, the value of this coefficient $(\nu)$ can be determined from the scale length of the spiral. If the spiral current structure crosses a density compensated front in temperature and salinity, the resulting frontal sheet will be deformed into a vertically wavy pattern corresponding to the offshore displacement. Because turbulent viscosity implies turbulent diffusivity, the water extruding across the initially vertical boundary will tend to mix with the receiving water mass. Between the intrusions the receiving water will tend to remain relatively unchanged. A vertical station, taken slightly shoreward of the initial frontal position, will show relatively homogeneous segments of the initial water mass broken, at regular intervals, with rounded intrusions of entering water. This salinity pattern is seen in Figure $3 b$ for the central intrusion only. The limits of intruding water are located at a depth interval of a quarter Ekman spiral (Figure 5), so that $S(f / 2 v)^{1 / 2}=\pi / 2$, which gives

$$
\nu=2 f S^{2} / \pi^{2}
$$

where $S$ is the vertical spacing between intrusion limits. The value of $13 \mathrm{~m}$ for $S$, from Figure $3 b$, produces a value for $\nu$ of

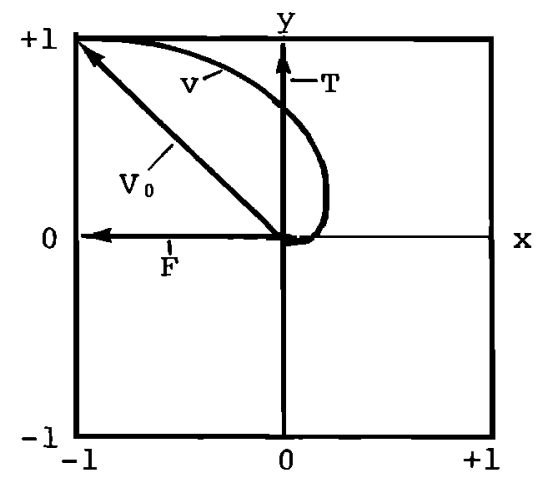

Fig. 6. View from above of vectors for pressure gradient force $(F)$, velocity at the level of the force $\left(V_{0}\right)$, velocity hodograph $(v)$, and net transport ( $T$ ) for the Green's function. Relative scales are used. 


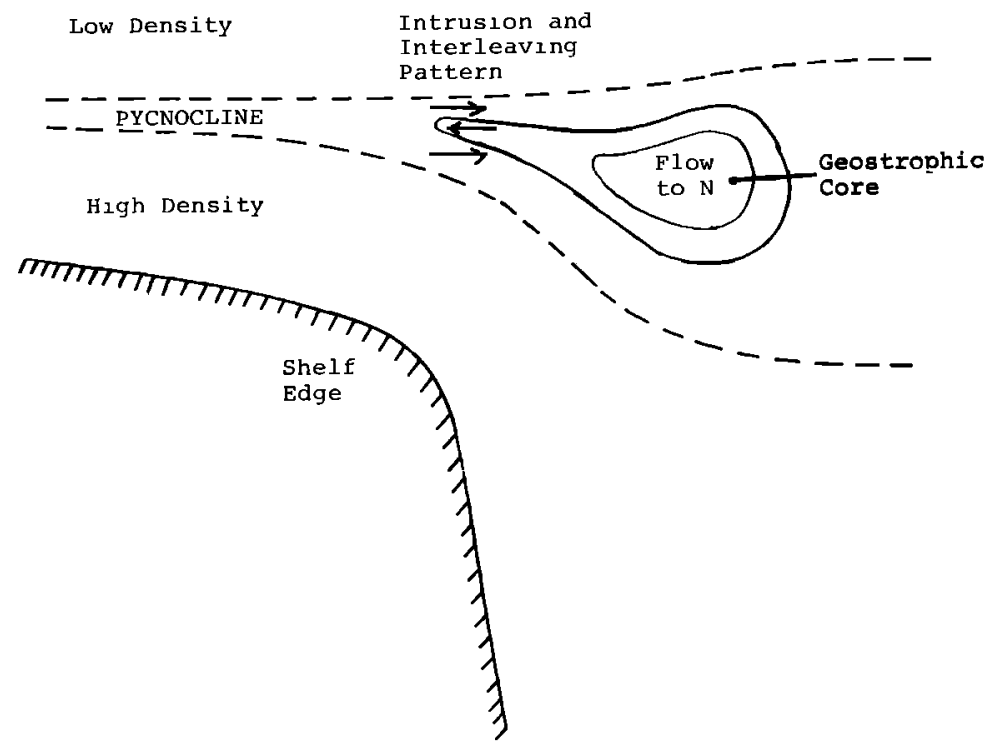

Fig. 7. Conceptual flow pattern for the continental shelf edge as discussed in the text. Solid contour lines represent isotachs of northward velocity, while arrows denote cross-shelf exchange. The pycnocline is contained within the dashed lines.

$30 \mathrm{~cm}^{2} / \mathrm{s}$, a value within the range of previously quoted values.

In another application, the flow pattern of Figure 7 contains a northerly oriented geostrophic core in the relative current. Such a flow could be a conduit in which young fish are transported from the region of Cape Hatteras to the latitude of the mouth of Chesapeake Bay. The young of some fish species thought to winter south of Cape Hatteras are found in the Chesapeake in the springtime before the migrating adults arrive (D. Haven, personal communication, 1980). In order for the relative flow pattern to transport the fish to the north, it must overcome the general southerly flow, which characterizes long-term averages of currents in the region [Iselin, 1955; Bumpus, 1973]. An examination of time series of observed currents shows that periods of little current are interspersed with southerly flow events [Beardsley and Butman, 1974; Ruzecki et al., 1976; Boicourt and Hacker, 1976]. There appear to be few northerly flow events, although Bumpus [1969] has noted reversals in the surface drift. As the value of mean current speed is about $5 \mathrm{~cm} / \mathrm{s}$, the mean speed between southerly flow events is somewhat less, and the relative northward flow speeds of up to $20 \mathrm{~cm} / \mathrm{s}$ in the geostrophic core can easily overcome this flow. The previous speed calculation indicates that the northward travel between Cape Hatteras and the latitude of the mouth of Chesapeake Bay would require about 11 days. A few more days would be required in the spring, with some time needed for cross-shelf transit. The mid-level flow on Figure 7 would inject the young fish preferentially into the middle level of the water column along the entire path. The primary requirement for the completion of the trip is a period of time of about 2 weeks between southerly flow events in the spring after formation of the shelf pycnocline.

\section{CONCLUSIONS}

The hydrographic signature of interleaving at the edge of the continental shelf is consistent with an interpretation based on Ekman dynamics, as expressed by Hidaka [1955]. The pressure forces driving the internal flow arise from horizontal variations in pycnocline thickness under hydrostatic conditions. If this interpretation is applied at the thermocline level by considering the fluid as infinite in extent vertically, the resulting flow has no net vertically integrated transport in the direction of greatest pycnocline thickness variation, but it exchanges water horizontally in a manner to reduce the pycnocline thickness contrast. A net transport is produced within the flow layer in a direction perpendicular to the greatest pycnocline variation. Applying the calculations to summertime conditions at the continental shelf edge of the Middle Atlantic Bight results in an interleaving pattern onshore and a geostrophic shore-parallel core current offshore, the difference in patterns depending on whether the vertical scale of horizontal pressure forces is large (offshore) or small (onshore) with respect to the Ekman scale depth. Where an interleaving pattern is present at a density compensating front, an estimate of a coefficient of eddy viscosity can be made from the vertical scale of the interleaving pattern. Estimates for the maximum speed of the geostrophic core and the coefficient of eddy viscosity in the example yield values of $20 \mathrm{~cm} \mathrm{~s}^{-1}$ and $30 \mathrm{~cm}^{2} \mathrm{~s}^{-1}$, respectively.

Acknowledgments. The survey used in section 3 was supported by the Bureau of Land Management contract AA-550-CT-6-62. Manuscript preparation was partially supported by the Virginia Institute of Marine Science. Comments from the editor and reviewers were valuable in adding clarity and context to the manuscript. Conversations with $\mathbf{E}$. P. Ruzecki were of help and encouragement. Typing by $S$. Crossley and drafting by $\mathbf{P}$. Smith are also appreciated.

\section{REFERENCES}

Beardsley, R. C., and B. Butman, Circulation on the New England continental shelf: Response to strong winter storms, Geophys. Res. Lett., 1(4), 181-184, 1974.

Beardsley, R. C., and C. N. Flagg, The water structure, mean cur- 
rents, and shelf water/slope water front on the New England continental shelf, Mem. Soc. R. Sci. Liege, Ser. 6, X, 209-225, 1976.

Bigelow, H. B., Studies of the waters on the continental shelf, Cape Cod to Chesapeake Bay, I, The cycle of temperature, Pap. Phys. Oceanogr. Meteorol., 2, 1-135, 1933.

Bigelow, H. B., and M. Sears, Studies of the waters on the continental shelf, Cape Cod to Chesapeake Bay, II, Salinity, Pap. Phys. Oceanogr. Meteorol., 4(1), 1-94, 1935.

Boicourt, W. C., and P. W. Hacker, Circulation on the Atlantic continental shelf of the United States, Cape May to Cape Hatteras, Mem. Soc. R. Sci. Liege, Ser. 6, X, 187-200, $19 ; 6$.

Bumpus, D., Reversals in the surface drift in the Middle Atlantic Bight area, Deep Sea Res., 16S, 17-23, 1969.

Bumpus, D., A description of the circulation on the continental shelf of the east coast of the United States, Progr. Oceanogr., 6, 111-156, 1973.

Cresswell, G. M., Quasi-synoptic monthly hydrography of the transition region between coastal and slope water south of Cape Cod, Mass., Rep. 67-35, Woods Hole Oceanogr. Inst., Woods Hole, Mass., 1967.

Curtin, T. B., Oceanographic field operations off North Carolina, summer survey, 2-12 August 1977, Rep. 79-2, 213 pp., Dep. of Mar. Sci. and Eng., North Carolina State Univ., Raleigh, 1979.

EG\&G, Environmental Consultants, Data report, Support hydrography cruise, May 1978, Eighth Quarterly Progress Report, New England Outer Continental Shelf Physical Oceanography Program, Append. C, Boston, December 1978.

Gordon, A. L., and F. Aikman III, Salinity maximum in the pycnocline of the Middle Atlantic Bight, Limnol. Oceanogr., 26(1), 123$130,1981$.

Hidaka, K., Wind circulation in a two-layer ocean, Jpn. J. Geophys., I(2), 33-45, 1955.

Horne, E. P. W., Interleaving at the subsurface front in the slope water off Nova Scotia, J. Geophys. Res., 83, 3659-3671, 1978.
Iselin, C., Coastal currents and the fisheries, Deep Sea Res., 3S, 474478, 1955.

Joyce, T. M., A note on the lateral mixing of water masses, J. Phys. Oceanogr., 7, 626-629, 1977.

Posmentier, E. S., and R. W. Houghton, Fine structure instabilities induced by double diffusion in the shelf/slope water front, $J$. Geophys. Res., 83, 5135-5138, 1978.

Posmentier, E. S., and R. W. Houghton, Springtime evolution of the New England shelf break front, $J$. Geophys. Res., 86, 4253-4259, 1981.

Ruzecki, E. P., C. S. Welch, J. Usry, and J. Wallace, The use of the EOLE satellite system to observe continental shelf circulation, paper presented at Eighth Annual Offshore Technology Conference, Am. Inst. of Mining, Met., and Petrol. Eng., Houston, Tex., 1976.

Ruzecki, E. P. C. S. Welch, and D. L. Baker, Seasonal meteorological and hydrographic conditions in the northern half of the Middle Atlantic Bight, in Middle Atlantic Outer Continental Shelf Environmental Studies, vol. II, Chemical and Biological Benchmark Studies, chap. 3, report to Bur. of Land Manage., U.S. Dep. of the Interior, contract 08550-CT-5-42, Va Inst. of Mar. Sci., Gloucester Point, Va., 1977.

Stommel, H., and K. N. Federov, Small scale structure in temperature and salinity near Timor and Mindanao, Tellus, 19(2), 306-325, 1967.

Turner, J. S., Salt fingers across a density interface, Deep Sea Res., 14, 599-611, 1967.

Voorhis, A. D., D. C. Webb, and R. C. Millard, Current structure and mixing in the shelf/slope water front south of New England, $J$. Geophys. Res., 81, 3695-3708, 1976.

(Received December 7, 1979; revised July 6, 1981; accepted July 14, 1981.) 